\title{
Multidrug Resistance in Large-Plasmid-Associated Presumptive Enterohaemorrhagic Escherichia coli Isolated from Contaminated Lake Water
}

\author{
Zakir Hossain ${ }^{1}$, Papia Sultana², Sudipta Deb ${ }^{3}$ and Monzur Morshed Ahmed ${ }^{1 *}$ \\ ${ }^{I}$ Industrial Microbiology Section, Institute of Food Science and Technology,Bangladesh Council of Scientific and Industrial Research, Dhaka, \\ Bangladesh, ${ }^{2}$ Department of Genetic Engineering and Biotechnology, Shahjalal University of Science and Technology, Sylhet, Bangladesh, \\ ${ }^{3}$ Department of Microbiology, Stamford University, Dhaka, Bangladesh
}

(Received 7 April 2011; Accepted 20 August 2011)

\begin{abstract}
To determine the presence of enterohaemorrhagic Escherichia coli (EHEC), 50 water samples of three different lakes in Dhaka, Bangladesh were studied. A total of 90 strains were examined thoroughly to isolate sorbitol non-fermenting (NSF) $E$. coli. Twelve of 90 isolates (13.3\%) from 5 samples were found to be sorbitol nonfermenter, which were further screened for rhamnose, cellobiose and sucrose fermentation. Eleven (12.2\%) of 90 isolates also tested negative for cellobiose and sucrose fermentation, while only $3(3.3 \%)$ of them were found to be rhamnose non-fermenting. Biochemical tests confirmed that $91.7 \%$ (11 of 12) of NSF strains were indole positive. Eleven NSF $E$. coli isolates survived at $45.5^{\circ} \mathrm{C}$ and mostly produced gas by fermentation within 24h. After antimicrobial susceptibility testing, $91.7 \%(n=11)$ of these isolates were found resistant to cephalexin, ampicillin and amoxicillin. Ceftazidime and nalidixic acid resistance was also observed in $75 \%(9$ of 12$)$ and $58.3 \%$ ( 7 of 12 ) isolates, respectively. Plasmid profile analysis revealed that nine $(\mathbf{7 5 \%})$ strains harboured large plasmids of $>35.8-140$ megadaltons (MDa), four (33.3\%) of which contained 60-MDa plasmid. Also, the large-plasmid-associated strains shared common behaviour in antimicrobial resistance and eight $(\mathbf{8 8 . 9 \%})$ of these were resistant to four or more antibiotics. Our data suggest a possible association of source water contamination in Bangladesh with multidrug-resistant (MDR) EHEC, which is alarming to public health.
\end{abstract}

Keywords: EHEC, water, sorbitol non-fermenting E. coli, large plasmid, MDR, public health

\section{Introduction}

Enterohaemorrhagic Escherichia coli (EHEC) are one of the most virulent types of bacteria that are now given significantly high importance among all food-borne pathogens ${ }^{1-4}$. EHEC are also known as shiga-toxin producing E. coli (STEC) or verocytotoxin (VT)-producing E. coli (VTEC) $)^{5}$. Although E. coli $\mathrm{O} 157: \mathrm{H} 7$ has been identified as the most commonly found serotype of EHEC in the environment, frequent prevalence of a large number of EHEC non-O157 serotypes both in the environment and in patients has also been reported ${ }^{6,7}$. Seropathotypes of EHEC are thought to be strongly associated with haemorrhagic colitis characterized by abdominal cramps, bloody diarrhea and dehydration. Other principal manifestations of illness in humans include heamolytic uraemic syndrome (HUS), which may lead to acute renal failure particularly among children and thrombotic thrombocytopeanic purpura (TTP) leading to various neurological disorders such as seizures, strokes and coma ${ }^{8}$. Cattle, sheep and goats are considered as major natural reservoirs of these pathogens and transmission to humans takes place through food such as uncooked meat, unpasteurized milk products and vegetables, or contaminated water?
Pathogenicity of EHEC can mainly be attributed to its shiga-like toxin $(S t x)$ encoded by $S t x_{1}$ or $S t x_{2}$ gene, and attachment and effacing (eae) gene encoding the virulence-associated 94-kDa protein called intimin, which acts as an adherence factor during an infection in host cells ${ }^{9}$. The eae gene is a member of the pathogenicity island known as locus of enterocyte effacement (LEE) located in the bacterial chromosome. Apart from these virulence factors, most EHEC strains carry a large plasmid (approximately 60-MDa) that consists of $h l y_{\text {EHEC }}$ gene involved in haemolytic activity through expression of pore-forming cytolysin, called haemolysin ${ }^{5,10}$. Presence of other large molecularweight plasmids implicated in pathogenesis has also been detected in EHEC serotypes ${ }^{11}$. Although most STEC serotypes as well as STEC $\mathrm{O} 157$ possess similar virulence properties that include shiga-toxin producing gene(s), eae gene and 60-MDa plasmid DNA, they have proven to be different in terms of other metabolic and growth characteristics. These include inability to ferment sorbitol within 24 hours and inability to produce $\hat{a}$ glucuronidase, which are more commonly seen in E. coli $\mathrm{O} 157: \mathrm{H} 7$ than other members of the group. Also this pathogen does not normally grow at temperatures higher than $44.5^{\circ} \mathrm{C}$ in $E$. coli growth media, such as $\mathrm{EC}$ broth ${ }^{12}$. In addition, EHEC O157 contains

*Corresponding author.

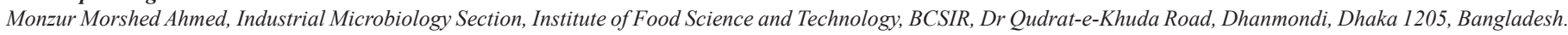
Phone: 88(0) 2 8614884. Mobile: 88(0)1552 636715.Email: monzur_29@yahoo.com 
a gene in the $r f b$ region of its genome, known as $r f b_{\mathrm{O} 157}$, which encodes the somatic antigen $\mathrm{O} 157^{13}$.

E. coli $\mathrm{O} 157: \mathrm{H} 7$ has been found sporadically in the environment as well as from the patients in developing countries as compared to a high prevalence of this pathogen in the developed world ${ }^{14-}$ ${ }^{16}$. However, Islam et al. ${ }^{5}$ reported a reasonably more significant prevalence of STEC O157 together with non-O157 serotypes among buffalo, cows and goats in Bangladesh. More detailed studies may be able to explain STEC related morbidity and the status of immune response in developing regions of the world. EHEC seropathotypes, especially E. coli $\mathrm{O} 157: \mathrm{H} 7$ are capable of causing illnesses upon ingestion of as small infectious dose as fewer than 50 organisms ${ }^{17}$. Therefore, any low prevalence of these bacteria in the susceptible sources of the environment other than cattle must not be ignored. Since water plays an inevitable role in transmitting these pathogens into human through fish, crops and other food products 8,18 , it is equally important to investigate the occurrence of EHEC in the water used for drinking, swimming and other necessities. There is strong evidence of presence of stx 1 , stx 2 and eae gene-positive E. coli $\mathrm{O} 157: \mathrm{H} 7$ in a large water source in India ${ }^{19}$. As no substantial data of surveillance addressing EHEC O157 and non-O157 in contaminated water of Bangladesh are currently available, it has become a priority to make systematic attempts to detect any prevalence of these strains in various local water sources.

The key objectives of this study were to detect and isolate EHEC from surface water in Dhaka, Bangladesh and in areas near the city and to reveal antimicrobial resistance in these strains. The study was also aimed at understanding the relation of antibiotic resistance to the molecular basis of the water isolates.

\section{Materials and Methods}

\section{Bacterial strains}

E. coli $\mathrm{ATCC} 8739$ and E. coli $\mathrm{O} 157: \mathrm{H} 7 \mathrm{NCTC} 12079$ were used in all experiments throughout this study as appropriate control strains (ATCC, American Type Culture Collection, USA; NCTC, National Collection of Type Cultures, United Kingdom). ATCC 8739 (Microbiologics ${ }^{\circledR}$, USA), as a non-toxigenic and non-plasmid containing strain ${ }^{20}$, was obtained from the Microbial Reference Culture Collection of the Food Microbiology Laboratory, BCSIR, and the NCTC 12079 strain was kindly provided by the Department of Microbiology, University of Dhaka, Bangladesh. Other bacterial strains, such as Bacillus cereus, Pseudomonas aeruginosa, Salmonella typhi and Vibrio cholerae used as controls in certain biochemical tests were previously isolated from the environment and maintained in the laboratory, where this study was conducted.

\section{Sampling}

A total of 50 water samples were aseptically collected from four different areas, Gulshan-Banani $(\mathrm{n}=20)$ and Dhanmondi $(\mathrm{n}=20)$ lakes located in Dhaka and two lakes of Jahangirnagar University $(n=10)$, Savar over a period between March and December 2010.
Water was obtained from about $10 \mathrm{~cm}$ depth of the surface level. All samples were maintained in sterile sample collection bottles (Schott Duran, Germany) with appropriate storage conditions and immediately transported to the laboratory, where they were stored at $4{ }^{\circ} \mathrm{C}$ until sample preparation within a day of collection.

\section{Selective enrichment and isolation of NSF E. coli}

A $100 \mathrm{ml}$ aliquot of each water sample was filtered through $0.45 \mathrm{im}$ pore-size cellulose nitrate filter (Sartorius AG, Germany) ${ }^{14}$ and the filter was suspended in $225 \mathrm{ml}$ modified tryptone soya broth (TSB) (Oxoid, England) supplemented with $20 \mathrm{mg} / \mathrm{L}$ novobiocin (Merck, Germany) $^{13,14}$. All samples were incubated with agitation at $120 \mathrm{rpm}$ and $37^{\circ} \mathrm{C}$ for $18 \mathrm{~h}$ and bacterial growth was confirmed based on the turbidity of the broth. A $0.1 \mathrm{ml}$ aliquot of $10^{-2}$ dilution of the TSB-enriched culture was plated onto sorbitol MacConkey agar (SMAC, Oxoid, England) with cefixime $(0.05 \mathrm{mg} / \mathrm{L})$ and potassium tellurite $(2.5 \mathrm{mg} / \mathrm{L})$ (CT-SMAC) and incubated for 24 hours at $42^{\circ} \mathrm{C}^{14,21,22}$. Colourless (sorbitol non-fermenting) colonies of 1-2 mm diameter from each plate were randomly selected and subjected independently to lactose fermentation in EC broth (HiMedia, India) containing bromothymol blue as an acid indicator for $24-48 \mathrm{~h}$ at $37^{\circ} \mathrm{C}^{23}$. Isolates that were capable of fermenting lactose were subsequently screened on eosin methylene blue (EMB) and MacConkey agar plates for confirmation of E. coli ${ }^{1}$.

Biochemical identification of potential EHEC O157 and nonO157

CT-SMAC derived sorbitol-negative isolates were subcultured on tryptone soya agar (TSA; HiMedia, India) and rescreened for sorbitol fermentation in carbohydrate fermentation broth supplemented with sorbitol and bromothymol blue dye to exclude any false positive results. All sorbitol-negative strains were presumed to be EHEC/STEC irrespective of the serotypes. Additionally, these isolates were tested for rhamnose, cellobiose and sucrose fermentation, and indole production to categorize NSF E. coli further.

\section{Bacterial survival study at high temperature}

Because $E$. coli $\mathrm{O} 157: \mathrm{H} 7$ does not normally grow at temperatures above $44.5^{\circ} \mathrm{C}^{12}$, this experiment was carried out with the sorbitolnegative strains isolated in the present study to screen for this important growth characteristic. A discrete colony of each strain was transferred to EC broth with Durham's tube and incubated aerobically for $48 \mathrm{~h}$ at $45.5^{\circ} \mathrm{C}^{24}$. Any turbidity of the broth was considered as survival of the bacteria at such high temperature. Formation of bubble(s) in the tube indicated the ability of the organism to produce gas by lactose fermentation at this temperature.

\section{Antimicrobial susceptibility testing}

Antimicrobial susceptibility was tested according to the method described by Bauer et al. ${ }^{25}$. The panel of antibiotic discs used was amoxycillin $(10 \mu \mathrm{g})$, ampicillin $(10 \mu \mathrm{g})$, ceftazidime $(30 \mu \mathrm{g})$, 
cephalexin $(30 \mu \mathrm{g})$, doxycycline $(30 \mu \mathrm{g})$, gentamycin $(10 \mu \mathrm{g})$, and sulphamethoxazole/ trimethoprim $(25 \mu \mathrm{g})$ [Oxoid, England];

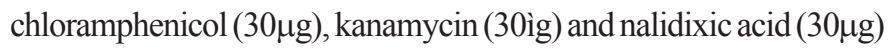
[HiMedia, India]. Susceptibility of each isolate to the above antimicrobial agents was assessed by interpretation of the diameter of zones of inhibition on Mueller-Hinton agar (Oxoid, England) according to performance standards set by Clinical and Laboratory Standards Institute (CLSI, USA $)^{26}$.

\section{Plasmid DNA extraction and analysis}

All isolates were grown aerobically overnight (about $18 \mathrm{~h}$ ) in TSB with $0.3 \%$ yeast extract at $37^{\circ} \mathrm{C}$. One millilitre of each broth culture was transferred to a $1.5 \mathrm{ml}$ microcentrifuge tube. Plasmid DNA extraction was done by alkaline lysis method of Kado and $\mathrm{Liu}^{27}$ with minor modification. Extracted DNA (27 il ) mixed with 3 il of loading buffer (10X Blue Juice ${ }^{\mathrm{TM}}$; Invitrogen, England) and was subjected to separation by $0.8 \%$ agarose gel electrophoresis. A horizontal submarine gel electrophoresis system (Biometra, USA) was used for this separation at a constant voltage (90V) for approximately $90 \mathrm{~min}$. Reference markers, pDK-9 (140-MDa), V517 (35.8-MDa) and plasmid DNA of NCTC 12079 (>60-MDa) were used to determine the molecular weight of plasmids extracted from the isolates. The electrophoresed gel was visualized by illumination on a UV transilluminator at $302 \mathrm{~nm}$ wavelength and the image was captured by a gel documentation system (Alpha Imager HP).

\section{Statistical analysis}

To validate the efficiency of an EC-broth mediated lactose fermentation step before using EMB and MacConkey agar media for confirmation of $E$. coli in this study, the percentages of sensitivity and specificity were calculated as follows:

$\%$ Sensitivity $=$ True positives $\times 100 /($ True positives + False negatives)

$\%$ Specificity $=$ True negatives $\times 100 /($ True negatives + False positives)

\section{Results and Discussion}

Several efforts have been made to detect and characterize enterohaemorrhagic E. coli in Bangladesh as described in earlier report ${ }^{5,15}$. These studies have described significant prevalence of these seropathotypes, including EHEC/STEC O157 and nonO157 in cattle- related sources. Serious implication of these bacteria with water contamination may pose a high risk to the local population, especially who maintain poor hygiene in their daily lives. It has become increasingly essential to know the status of EHEC serotypes in various water sources of Dhaka, including lakes commonly used by a large number of inhabitants. Since these lakes also serve as a source of fish industry in the city, occurrence of any toxigenic strain of EHEC in the water might have direct impact on the food chain. Our present study was, therefore, designed to isolate EHEC from water of some selected lakes and describe their phenotypic and genotypic properties to identify prospective challenges relating to pathogenicity, outbreak and clinical intervention, particularly antimicrobial resistance.

\section{Identification and recovery of presumptive EHEC}

After screening of sorbitol-negative (colorless) isolates from CTSMAC and in EC broth, lactose-fermenting bacteria were grown on EMB and MacConkey agar media to test for confirmation of E. coli. A total of 90 E. coli isolates from 50 water samples (Table 1) were obtained. Twelve of 90 isolates (13.3\%) from 5 samples were found to be sorbitol-non fermenter (Table 2). While 11 of 42 isolates of E. coli obtained from Gulshan-Banani lake and I of 18 isolates from Jahangirnagar University lake were sorbitol nonfermenter, none of the isolates $(\mathrm{n}=30$ ) from Dhanmondi lake could be classified as the same (Table 1). Only these true-positive (NSFE. coli) isolates were recruited in further experiments. Eleven $(12.2 \%)$ isolates also tested negative for cellobiose and sucrose fermentation. Only 3 of the 12 NSF isolates (3.3\%) were found to be rhamnose non-fermenter (Table 2). E. coli ATCC 8739 was found negative for only sucrose, whereas E. coli NCTC 12079 could not ferment any of the sugars except lactose (Table 2). Further biochemical tests with all these strains showed characteristics of E. coli. Apart from only one (GLW19b), all other strains ( $\mathrm{n}=11)$ were indole positive.

Although a large number of isolates from water samples tested positive for E. coli, very few of them could successfully be identified as non-sorbitol-fermenting (NSF) strains. It was difficult to select true NSF (colourless) colonies from SMAC plates due to overwhelming growth of sorbitol fermenters (pink colonies) on many plates. Consequently, many of the presumptive NSF $E$. coli isolates were found to be sorbitol fermentors when discretely tested for sorbitol fermentation in the broth. In a study conducted on E. coli $\mathrm{O} 157: \mathrm{H} 7$ in food based on different isolation techniques, SMAC yielded the highest number of false positive isolates $(57.3 \%)$ as compared to other media ${ }^{28}$. Therefore, screening by

Table 1. Percentage of NSF E. coli isolates according to their sources of isolation

\begin{tabular}{lccc}
\hline Source & $\begin{array}{c}\text { Total number of } \\
\text { samples }(\mathrm{n}=50)\end{array}$ & $\begin{array}{c}\text { Number (\%) of NSF-E. coli } \\
\text { samples }(\mathrm{n}=6)\end{array}$ & $\begin{array}{c}\text { Percentage of NSF-E. coli isolates } \\
(\mathrm{NSF} / \text { Total isolates })(\mathrm{n}=90)\end{array}$ \\
\hline Gulshan-Banani & 20 & $5(25)$ & $26.2 \%(11 / 42)$ \\
Dhanmondi & 20 & $\mathrm{ND}$ & $\mathrm{ND}(0 / 30)$ \\
J. University & 10 & $1(10)$ & $5.6 \%(1 / 18)$ \\
ND, not detected & & & \\
\hline
\end{tabular}


Table 2. Carbohydrate fermentation of selected NSF E. coli strains and controls

\begin{tabular}{|c|c|c|c|c|c|}
\hline Control/Isolate & Lactose & Sorbitol & Rhamnose & Cellobiose & Sucrose \\
\hline ATCC 8739 & + & + & + & + & - \\
\hline NCTC 12079 & + & - & - & - & - \\
\hline GLW1b & + & - & + & - & - \\
\hline GLW1c & + & - & + & - & - \\
\hline GLW4c & + & - & + & - & - \\
\hline GLW11b & + & - & + & - & - \\
\hline GLW18a & + & - & + & - & - \\
\hline GLW18d & + & - & - & - & - \\
\hline GLW19b & + & - & + & + & + \\
\hline
\end{tabular}

carbohydrate fermentation separately in this study enhanced the possibility of isolation of the targeted bacteria. Addition of a lactose fermentation step prior to screening on EMB and MacConkey agar media helped achieve good sensitivity and specificity $(94.7 \%$ and $90.4 \%$ respectively; Table 3$)$ of E. coli isolation as most of the presumptive E. coli in EC broth tested true positive in these agar media. Also this step was useful for more confirmatory isolation of these bacteria because growth of a potentially large number of acid-producing bacteria in EC broth suppressed that of any non-E. coli isolate picked by chance from CT-SMAC. Such isolation would have been difficult if directly streaked on EMB or MacConkey agar due to counterfeit negative result for overlapping growth of other bacteria on the same media. It should be noted that the $\mathrm{EC}$ broth-assisted primary screening for $E$. coli was carried out at $37^{\circ} \mathrm{C}$ instead of $44.5^{\circ} \mathrm{C}-45.5^{\circ} \mathrm{C}$ in order to prevent any heat-induced inhibition of growth ${ }^{24}$, which has been broadly discussed later in this article. Indole test is believed to be the finest confirmatory test for E. coli strains ${ }^{1}$. Therefore, indole production by $91.7 \%$ (11/12) sorbitol-negative isolates further supported the above observations in relation to the presence of these strains.

Table 3. Evaluation of primary screening for E. coli by EC broth

\begin{tabular}{lc}
\hline Type of isolates & Total number $(\%)$ \\
\hline True positives & $90(84.1)$ \\
False positives & $17(15.9)$ \\
True negatives & $160(97)$ \\
False negatives & $5(3)$ \\
\hline
\end{tabular}

In this study, carbohydrates that many members of EHEC serogroups including E. coli $\mathrm{O} 157: \mathrm{H} 7$ have been unable to ferment according to previous observations ${ }^{1,29}$ were carefully selected. Therefore, non-fermentation of these sugars served as a good phenotypic marker for presumptive identification of the targeted bacteria. The three E. coli isolates (GLW18d, GLW19c and JLW8), which tested negative for sorbitol, rhamnose, cellobiose and sucrose, were potential candidates of STEC serotype O157 because the result resembled that of the positive control (NCTC 12079). These results indicate the possible occurrence of more than one serotype of EHEC in these isolates.

\section{Survival pattern of isolates at $45.5^{\circ} \mathrm{C}$}

The aim of this experiment was to check the effect of high temperature $\left(45.5^{\circ} \mathrm{C}\right)$ on the growth of the isolates. Eleven of the $12(91.7 \%)$ strains grew in EC broth at such high temperature within 24 hours although one of them (GLW19b) exhibited poor growth (Table 4), which was indicated by low turbidity of the broth according to visual observation. Meanwhile, gas production was not detected in $4(33.3 \%)$ tubes including that inoculated with the non-growing strain, JLW8. The positive control strain (NCTC 12079) grew slowly and produced very small amount of gas (Table 4).

Table 4. Growth of isolates at $45.5^{\circ} \mathrm{C}$ and corresponding gas production due to fermentation

\begin{tabular}{lcc}
\hline Tested strain & Status of growth at $45.5^{\circ} \mathrm{C}$ & Gas production \\
\hline ATCC 8739 & + & $\mathrm{Y}$ \\
NCTC 12079 & $\sim+$ & $\sim \mathrm{Y}$ \\
GLW1a & + & $\mathrm{Y}$ \\
GLW1b & + & $\mathrm{Y}$ \\
GLW1C & + & $\mathrm{Y}$ \\
GLW4a & + & $\mathrm{N}$ \\
GLW4b & + & $\mathrm{N}$ \\
GLW4c & + & $\mathrm{Y}$ \\
GLW11b & + & $\mathrm{Y}$ \\
GLW18a & + & $\mathrm{Y}$ \\
GLW18d & + & $\mathrm{Y}$ \\
GLW19b & & $\mathrm{N}$ \\
GLW19c & + & $\mathrm{Y}$ \\
JLW8 & - & $\mathrm{N}$
\end{tabular}

Symbols: +, good growth; +, poor growth; -, no growth; Y, gas positive; $\sim$ Y, poor gas production; $\mathrm{N}$, gas negative 
The growth of E. coli $\mathrm{O} 157: \mathrm{H} 7$ being the most important serotype of EHEC is believed to be abrogated by extreme temperatures, such as above $44.5^{\circ} \mathrm{C}^{30,31}$. Almost all other E. coli have ability to grow at this temperature at least slowly. This is why such high temperatures are used to recover E. coli from foods ${ }^{32}$. Doyle \& Schoeni ${ }^{24}$ reported considerably poor growth of $E$. coli $\mathrm{O} 157: \mathrm{H} 7$ in trypticase soya broth with a high generation time of $1.18 \mathrm{~h}$ (average) after incubation of $24-48 \mathrm{~h}$ at temperatures between $44-$ $45^{\circ} \mathrm{C}$ and no growth at all at $45.5^{\circ} \mathrm{C}$ due to reduced endurance. Therefore, the survival study by maintaining the incubation temperature constantly at $45.5^{\circ} \mathrm{C}$, in this experiment, was thought to be partly capable of identifying STEC O157 from all the 12 NSF E. coli strains based on this significant growth characteristic. Our observations were different from the data of previous findings ${ }^{24,31}$ because almost all isolates including the positive control strain (NCTC 12079) could survive and grow at $45.5^{\circ} \mathrm{C}$ within 24 hours of incubation. Poor growth of the two strains (GLW19b and positive control) does, however, inform that the corresponding generation time probably increased causing little or no gas production by the organisms. Similarly, non-gas production by four strains (GLW4a, GLW4b, GLW19b and JLW8) suggests that such high temperature could possibly interfere with normal metabolic activity of the isolates. Addition of a suitable dye in the broth would have helped confirm any acid production by fermentation under the thermal stress.

\section{Multidrug-resistant (MDR) Pattern}

Antibiotic susceptibility pattern of the 12 presumptive EHEC isolates was determined based on the zones of inhibition observed in the corresponding plates. Results were compared to that obtained from the test done with the two control strains, E. coli (ATCC 8739) and E. coli O157:H7 (NCTC 12079). Table 5 presents the determined susceptibility of the isolates and the control strains to the ten antibiotics used in this study as mentioned earlier. While NCTC 12079 was resistant to only ampicillin, the other control strain, ATCC 8739 was susceptible to nearly all antibiotics. Among the isolates, $91.7 \%(\mathrm{n}=11)$ showed resistance to cephalexin, ampicillin and amoxycillin. Ceftazidime and nalidixic acid resistance was shown by $75 \%$ $(\mathrm{n}=9)$ and $58.3 \%(\mathrm{n}=7)$ isolates, respectively. Similarly, 50\% isolates revealed resistance to sulphamethoxazole/ trimethoprim and kanamycin. A total of $5(41.7 \%)$ strains that were found resistant to cephalexin also exhibited resistance to doxycycline. On the contrary, chloramphenicol and gentamycin were found to be the most active drugs in this assay to which none of the isolates could show resistance in the given period $(24 \mathrm{~h})$. Based on this information, 91.7\% $(\mathrm{n}=11)$ presumptive EHEC strains were resistant to four or more conventional antibiotics (Table 5).
Table 5. Antimicrobial susceptibility status among the isolates and the control strains

\begin{tabular}{lcccccccccc}
\hline Strain ID & C & NA & SXT & CL & CAZ & DO & GN & K & AMP & AML \\
\hline ATCC 8739 & S & S & S & I & S & S & S & S & S & I \\
NCTC 120799 & S & S & S & I & S & S & S & S & R & I \\
GLW1a & S & I & R & R & R & R & S & R & R & R \\
GLW1b & S & I & R & R & R & R & S & R & R & R \\
GLW1c & S & R & S & R & R & R & S & R & R & R \\
GLW4a & S & R & S & R & R & S & S & R & R & R \\
GLW4b & S & R & I & R & R & S & S & R & R & R \\
GLW4c & S & I & R & R & R & I & S & I & R & R \\
GLW11b & S & R & S & R & R & S & S & S & R & R \\
GLW18a & S & S & S & R & R & S & S & S & R & R \\
GLW18d & S & R & R & R & S & R & S & S & S & I \\
GLW19b & S & I & S & R & S & S & S & I & R & R \\
GLW19c & I & R & R & R & I & R & S & I & R & R \\
JLW8 & S & R & R & I & R & S & S & R & R & R \\
\hline
\end{tabular}

C, Chloramphenicol; NA, Nalidixic Acid; SXT, Sulphamethoxazole; CL, Cephalexin; CAZ, Ceftazidime; DO, Doxycycline; GN, Gentamycin; K, Kanamycin; AMP, Ampicillin; AML, Amoxycillin; S, Sensitive; I, Intermediate; R, Resistant

The above data relating to the antibiotic susceptibility of the isolates is largely supported by past findings, where a large number of STEC O157 strains have been found highly resistant to many of the antibiotics used in this study, including ampicillin, amoxycillin, nalidixic acid and tetracycline/doxycycline. Majority of those strains have been sensitive to gentamycin and chloramphenicol ${ }^{16,33,34}$. Those studies did not, however, report any resistance of EHEC to sulphamethoxazole/trimethoprim as found in the present study among $50 \%$ isolates $(n=6)$ (Table 5). Because environmentally isolated EHEC/STEC strains in the past showed quite similar antimicrobial resistance pattern as justified above, our observations indicate the prevalence of multipleantibiotic-resistant potential EHEC strains in the surface water. This scenario strongly informs that extensive and inappropriate use of these antibiotics in the community and in livestock may be the predominant cause of such alarming resistance ${ }^{35-37}$, which should be taken on board to improve local antibiotic-use policy for treatment in future.

\section{Detection of large-molecular-weight plasmid DNA}

After agarose gel electrophoresis, distinct bands of plasmid DNA were analysed. Based on the analysis, all 12 isolates harboured plasmids (> 2-MDa). Meanwhile, 4 (33.3\%) of them (GulshanBanani lake isolates) were found to contain 60-MDa plasmid (Fig. 1.A, B). The largest molecular-weight plasmids ( $>140-\mathrm{MDa}$ ) were detected in 2(16.7\%) strains (Fig. 1.B, C) isolated from samples of two different sources (Gulshan-Banani and J. University lakes), one of which also possessed a plasmid of $>35.8$-MDa (Fig. 1.C). Besides, 3 (25\%) isolates (Gulshan-Banani lake) were found to harbour > 35.8-MDa plasmid (Fig. 1.A). 

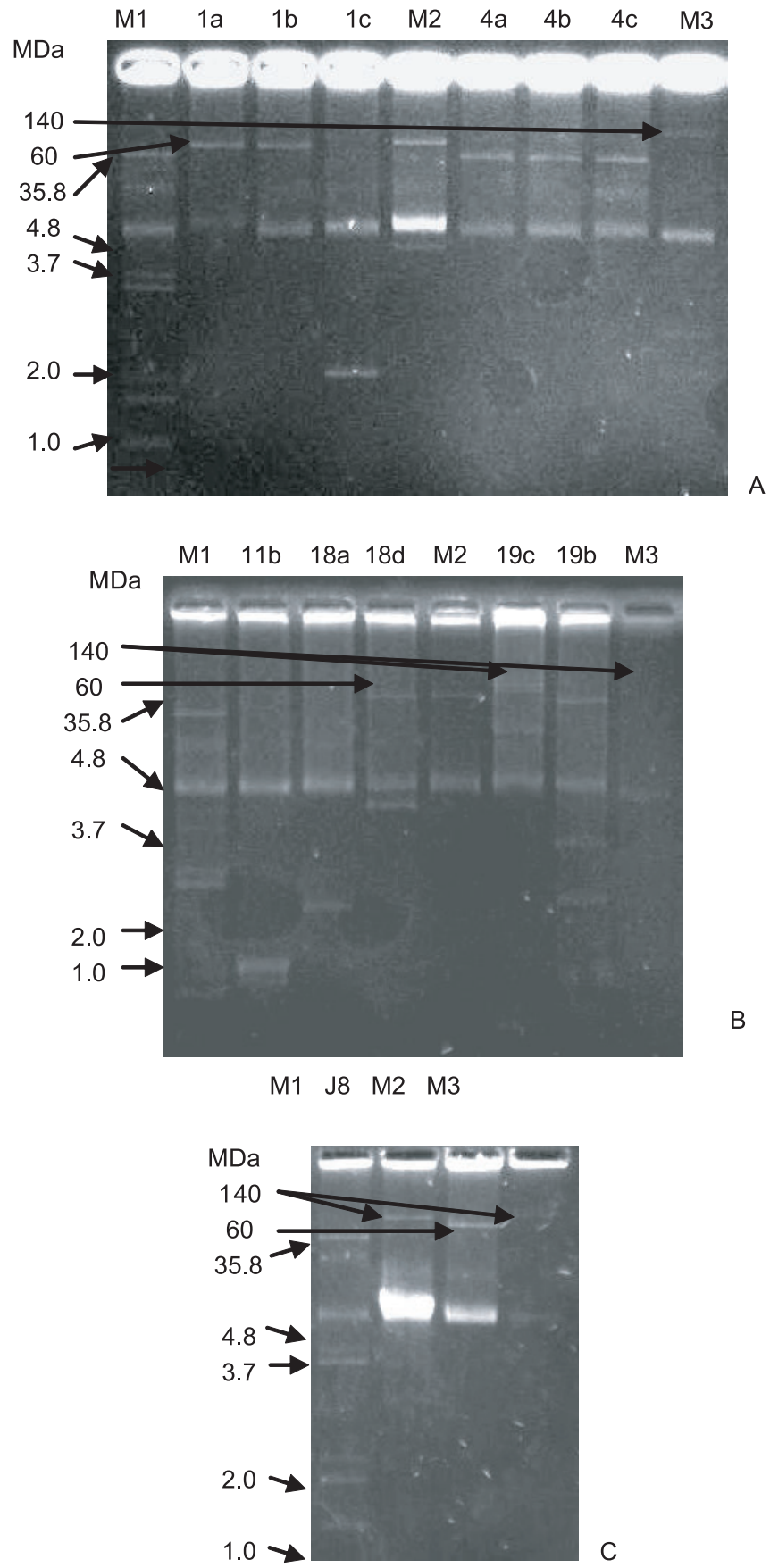

Figure 1. Plasmid profiles of water isolates $(n=12)$ after separation by agarose gel electrophoresis. (A) Lanes: M1, molecular weight marker, V517 (35.8-MDa being the largest); $1 a$ and 1b, isolates: GLWIa and GLWIb (60-MDa); 1c, isolate: GLWIc (>2-MDa); M2, molecular weight marker, NCTC 12079 (>60-MDa); 4a, 4b and 4c, isolates: GLW4a, GLW4b and GLW4c (>35.8-MDa); M3, molecular weight marker, $p D K-9$ (140-MDa being the largest). (B) Lanes: $M 1$, as above; $11 b$, isolate: $G L W 11 b(>2-M D a,>1.8-M D a$ and < 1-MDa); 18a, isolate GLW18a $<3.4-M D a) ; 18 d$ and $19 b$, isolates GLW18d and GLW19b (60-MDa for both; 4.8-MDa and $<$ 4.8-MDa \& < 3.7-MDa respectively); $M 2$, as above; 19 c, isolate: GLW19c (>140-MDa, <35.8-MDa and > 1-MDa); M3, as above. (C) Lanes: M1, as above; J8, isolate: JLW8 (140-MDa and > 35.8$M D a) ; M 2$ and M3, as above.

\section{Relationship between large plasmid and antimicrobial resistance}

Present study revealed that 9 (75\%) of the 12 isolates studied for antibiotic reistance harboured large-molecular-weight plasmids within the range of $>35.8-140 \mathrm{MDa}$. Figure 2 highlights that $55.6 \%$ $(\mathrm{n}=5)$ of these strains were resistant to nalidixic acid and kanamycin, and $66.7 \%(\mathrm{n}=6)$ showed resistance to sulphamethoxazole/trimethoprim and ceftazidime. Surprisingly, cephalexin, ampicillin and amoxycillin were identified as the most ineffective drugs against these strains as nearly $90 \%(n=8)$ of the large-plasmid-containing strains sustained their growth when tested with these antibiotics. Doxycycline resistance was observed in $44.4 \%(\mathrm{n}=4)$ of these isolates. Only chloramphenicol and gentamycin were inhibitory to all strains bearing large plasmids. Therefore, a total of 8 strains constituting $88.9 \%$ of those largeplasmid isolates showed resistance to four or more antibiotics. Furthermore, nalidixic acid and sulphamethoxazole resistance, as in Table 5, was revealed in both $>140$-MDa plasmid-containing isolates (GLW19c and JLW8). Cephalexin was not active against all four 60-MDa-plasmid containing isolates (GLW1a, GLW1b, GLW18d and GLW19b). In addition, 3 of 4 were resistant to sulphamethoxazole and doxycycline and 2 of 4 showed resistance to ceftazidime and kanamycin. The 3 isolates, which contained $>$ 35.8-MDa-plasmid DNA(GLW4a, GLW4b \& GLW4c), had similar pattern of resistance to mainly cephalexin, ceftazidime, ampicillin and amoxycillin. Except one strain containing 60-MDa plasmid (GLW18d), all isolates were found resistant to ampicillin and amoxycillin. Also, resistance to sulphamethoxazole/trimethoprim, doxycycline and kanamycin was more common among these nine strains than the others with small plasmid DNA.

Presence of large-molecular weight plasmid DNA has been

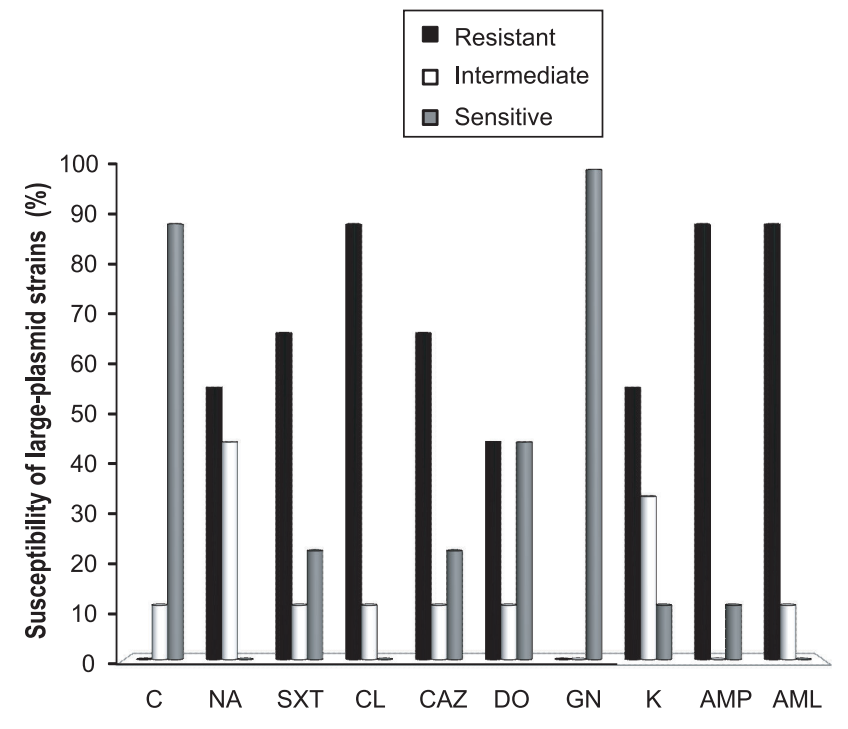

Name of antibiotic discs used

Figure 2. Antimicrobial susceptibility pattern of nine potential EHEC strains having large-molecular-weight plasmids, in three categories (resistant, intermediate and sensitive). Cephalexin $(C L)$, ampicillin $(A M P)$ and amoxycillin (AML) resistance was observed in the highest number $(88.9 \%$; $n=8)$ of these isolates. 
considered to be an important genotypic parameter in the detection of serogroups of shiga-toxin producing $E$. coli or EHEC in the environment. It is because the virulence-associated protein, haemolysin is encoded by the $h l y$ gene of this plasmid ${ }^{38}$. Therefore, experiments have been designed to detect this gene for confirmation of EHEC in many studies ${ }^{14,38,39}$. Though $h l_{\text {EHEC }}$ gene-specific assay by a suitable PCR (polymerase chain reaction) method was not performed in this study, detection of $60-\mathrm{MDa}$ plasmid in $33.3 \%$ (4) of the sorbitol-negative $E$. coli isolates has offered a first-round evidence of the potential prevalence of EHEC O157 or non-O157 in these water samples as justified by previous data $^{12}$. It is also worth knowing that some 'atypical EHEC' do not possess this plasmid and there is evidence of the presence of other large plasmids in E. coli $\mathrm{O} 157: \mathrm{H} 7^{1}$. Therefore, absence of 60-MDa plasmid in other strains in this study does not confirm whether those are non-enterohaemorrhagic $E$. coli. Based on our observations, the isolates containing plasmids of large molecular weights are potential members of EHEC and they may be virulenceassociated as well as toxigenic ${ }^{11}$. Association of plasmid DNA with antimicrobial resistance of $E$. coli as well as EHEC was described earlier ${ }^{16}$. Particularly, implication of large plasmid with multiple-drug resistance was broadly highlighted ${ }^{11}$. In the present study, we have successfully isolated nine large-plasmid containing strains, which showed remarkable resistance to a panel of carefully chosen antibiotics. An attempt has been made to establish a relationship of these plasmids with antibiotic resistance among the strains. Overall findings also report a possible association of EHEC with the lake water contamination in Dhaka. Further assays are being carried out to confirm these results. This study refers to the first survey of shiga-toxin producing E. coli in the source water of Bangladesh.

\section{Conclusions}

As contaminated surface water in Bangladesh can be a potential source of multidrug-resistant EHEC strains, it is now important to focus on more comprehensive investigations to determine the status of these bacteria in the environment. Detailed understanding of vertical evolution in these pathogens may also help assess the magnitude of antibiotic resistance and prospective public-health risks associated with it.

\section{Acknowledgements}

This research was funded and supported by Bangladesh Council of Scientific \& Industrial Research (BCSIR). The authors gratefully acknowledge Professor Dr. Md. Mahfuzul Hoque from the Department of Microbiology, University of Dhaka and Dr. Kaisar Ali Talukder from the Enteric Microbiology Laboratory, International Centre for Diarrhoeal Disease Research, Bangladesh (ICDDR,B) for their kind advice regarding this work and for providing some reference strains. The authors also thank the Scientific Officers, Khandaker Rayhan Mahbub and Md. Fakruddin, and all other members of research at the Industrial
Microbiology Section, Institute of Food Science and Technology, BCSIR for their compassionate cooperation during this study.

\section{References}

1. Nataro JP and Kaper JB. 1998. Diarrheagenic Escherichia coli. Clin Microbiol Rev. 11: 142-201.

2. Welinder-Olsson C and Kaijser B. 2005. Enterohemorrhagic Escherichia coli (EHEC). Scand J Infect Dis. 37: 405-416.

3. Raji MA, Minga U and Machangu R. 2006. Current epidemiological status of enterohaemorrhagic Escherichia coli O157:H7 in Africa. Chin Med J. 119(3): 217-222.

4. Hussein HS. 2007. Prevalence and pathogenicity of Shiga toxinproducing Escherichia coli in beef cattle. J Anim Sci. 85: E63-E72.

5. Islam MA, Mondol AS, de Boer E, Beumer RR, Zwietering MH, Talukder KA and Heuvelink AE. 2008. Prevalence and genetic characterization of Shiga toxin-producing Escherichia coli isolates from slaughtered animals in Bangladesh. Appl Environ Microbiol. 74: $5414-5421$

6. Pradel N, Livrelli V, de Champs C, Palcoux J, Reynaud A, Scheutz F, Sirot J and Joly B Forestier C. 2000. Prevalence and characterization of Shiga toxin-producing Escherichia coli isolated from cattle, food, and children during a one-year prospective study in France. J Clin Microbiol. 38: 1023-1031.

7. Blanco JE, Blanco M, Alonso MP, Mora A, Dahbi G, Coira MA and Blanco J. 2004. Serotypes, virulence genes, and intimin types of Shiga toxin (verotoxin)-producing Escherichia coli isolates from human patients: prevalence in Lugo, Spain, from 1992 through 1999. $J$ Clin Microbiol 42: 311-319.

8. Bach SJ, McAllister TA, Veira DM, Gannon VPJ and Holley RA. 2002. Transmission and control of Escherichia coli O157:H7-A review. Can J Anim Sci. 82: 475-490.

9. Doyle EM, Archer J, Kaspar CW and Weiss R. 2006. Human illness caused by E. coli O157:H7 from food and non-food sources. FRI Briefings. Available at: http://fri.wisc. edu/docs/pdf/FRIBrief_ EcoliO157H7humanillness.pdf. Accessed 3 February 2011.

10. Fratamico PM, Sackitey SK, Wiedmann M and Deng MY. 1995. Detection of Escherichia coli O157:H7 by multiplex PCR. J Clin Microbiol. 33: 2188-2191.

11. Smith S, Aboaba OO, Odeigha P, Shodipo K, Adeyeye JA, Ibrahim A, Adebiyi T, Onibokun H and Odunukwe NN. 2003. Plasmid profile of Escherichia coli 0157:H7 from apparently healthy animals. Afr $J$ Biotechnol. 2(9): 322-324.

12. Doyle MP and Beuchat LR, eds. 2007. In Food Microbiology: Fundamentals and Frontiers, pp 249-269. ASM Press, Washington D.C.

13. Jamshidi A, Bassami MR and Rasooli M. 2008. Isolation of Escherichia coli 0157:H7 from ground beef samples collected from beef markets, using conventional culture and polymerase chain reaction in Mashhad, northeastern Iran. Iran J Vet Res. 9(1): 72-76.

14. Bopp DJ, Sauders BD, Waring AL, Ackelsberg J, Dumas N, BraunHowland E, Dziewulski D, Wallace BJ, Kelly M, Halse T, Musser KA, Smith PF, Morse DL and Limberger RJ. 2003. Detection, isolation, and molecular subtyping of Escherichia coli O157:H7 and Campylobacter jejuni associated with a large waterborne outbreak. $J$ Clin Microbiol. 41: 174-180.

15. Islam MA, Heuvelink AE, de Boer E, Sturm PD, Beumer RR, Zwietering MH, Faruque ASG, Haque R, Sack DA and Talukder KA. 2007. Shiga toxin-producing Escherichia coli isolated from patients with diarrhoea in Bangladesh. J Med Microbiol 56: 380-385.

16. Chigor VN, Umoh VJ, Smith SI, Igbinosa EO and Okoh AI. 2010. Multidrug resistance and plasmid patterns of Escherichia coli $\mathrm{O} 157$ and other $E$. coli isolated from diarrhoeal stools and surface waters from some selected sources in Zaria, Nigeria. Int J Environ Res Public Health. 7: 3831-3841. 
17. Armstrong GL, Hollingsworth J and Morris, Jr JG. 1996. Emerging foodborne pathogens: Escherichia coli O157:H7 as a model of entry of a new pathogen into the food supply of the developed world. Epidemiol Rev. 18: 29-51.

18. Ferens WA and Hovde CJ. 2011. Escherichia coli O157:H7: Animal reservoir and sources of human infection. Foodborne Pathog Dis. 8(4): 465-487.

19. Hamner S, Broadaway SC, Mishra VB, Tripathi A, Mishra RK, Pulcini E, Pyle BH and Ford TE. 2007. Isolation of potentially pathogenic Escherichia coli O157:H7 from the Ganges River. Appl Environ Microbiol. 73: 2369-2372.

20. Romick TL, Lindsay JA and Busta FF. 1987. A visual DNA probe for detection of enterotoxigenic Escherichia coli by colony hybridization. Lett Appl Microbiol. 5: 87-90.

21. McDonough PL, Rossiter CA, Rebhun RB, Stehman SM, Lein DH and Shin SJ. 2000. Prevalence of Escherichia coli O157:H7 from cull dairy cows in New York state and comparison of culture methods used during preharvest food safety investigations. J Clin Microbiol. 38: $318-322$.

22. Ulukanli Z, Cavli P and Tuzcu M. 2006. Detection of Escherichia Coli O157:H7 from beef doner kebabs sold in Kars. J Sci. 19(2): 99104.

23. Hugh $\mathrm{R}$ and Leifson E. 1953. The taxonomic significance of fermentative versus oxidative metabolism of carbohydrates by various gram-negative bacteria. J Bacteriol. 66: 24-26.

24. Doyle MP and Schoeni JL. 1984. Survival and growth characteristics of Escherichia coli associated with hemorrhagic colitis. Appl Environ Microbiol. 48: 855-856.

25. Bauer AW, Kirby WM, Sherris JC and Turck M. 1966. Antibiotic susceptibility testing by a standardized single disc method. Am J Clin Pathol 45: 493-496.

26. Clinical and Laboratory Standards Institute. 2007. Performance standards for antimicrobial susceptibility testing; seventeenth informational supplement. M100-S17. 27(1)

27. Kado CI and Liu ST. 1981. Rapid procedure for detection and isolation of large and small plasmids. J Bacteriol. 145: 1365-1373.

28. Manafi M and Kremsmaier B. 2001. Comparative evaluation of different chromogenic/ fluorogenic media for detecting Escherichia coli $\mathrm{O} 157: \mathrm{H} 7$ in food. Int $J$ Food Microbiol. 71: 257-262.
29. Leclercq A, Lambert B, Pierard D and Mahillon J. 2001. Particular biochemical profiles for enterohemorrhagic Escherichia coli O157:H7 isolates on the ID 32E system. J Clin Microbiol. 39: 11611164.

30. Padhye NV and Doyle MP. 1992. Escherichia coli O157:H7epidemiology, pathogenesis, and methods for detection in food. $J$ Food Prot. 55: 555-565.

31. Ishii S, Meyer KP and Sadowsky MJ. 2007. Relationship between phylogenetic groups, genotypic clusters, and virulence gene profiles of Escherichia coli strains from diverse human and animal sources. Appl Environ Microbiol. 73: 5703-5710.

32. Feng P, Weagant SD and Grant MA. 1998. Enumeration of Escherichia coli and the coliform bacteria. In Bacteriological Analytical Manual. $8^{\text {th }}$ Edition. Chapter 4. Available at: http://www.fda.gov/food/ scienceresearch/LaboratoryMethods/Bacterio logicalAnalytical ManualBAM/ucm064948.htm. Accessed 11 January 2010.

33. Nizza S, Mallardo K, Marullo A, Iovane V, de Martino L and Pagnini U. 2010. Antibiotic susceptibility of haemolytic E. coli strains isolated from diarrhoeic faeces of buffalo calves. Ital J Anim Sci. 9(26): 134137.

34. Chattopadhyay UK, Gupta S and Dutta S. 2003. Search for shiga toxin producing Escherichia coli (STEC) including 0157:H7 strains in and around Kolkata. Indian J Med Microbiol. 21: 17-20.

35. Lewis R. 1995. The rise of antibiotic-resistant infections. In FDA Consumer Magazine. Available at: http://dwb4.unl.edu/chem/ chem $869 \mathrm{k} / \mathrm{chem} 869 \mathrm{klinks} / \mathrm{www}$. fda.gov/fdac/ features $/ 795$ antibio. html. Accessed 23 March 2011.

36. Angulo FJ, Nargund VN and Chiller TC. 2004. Evidence of an association between use of anti-microbial agents in food animals and anti-microbial resistance among bacteria isolated from humans and the human health consequences of such resistance. J Vet Med. 51: 374-379.

37. Anonymous. Antibiotic Resistance. In Health Canada. Available at: http://www. enotalone.com/article/10229.html. Accessed 3 April 2011.

38. Muller EE, Grabow WOK and Ehlers MM. 2003. Immunomagnetic separation of Escherichia coli O157:H7 from environmental and wastewater in South Africa. Water SA. 29(4): 427-432.

39. Paton AW and Paton JC. 1998. Detection and characterization of Shiga toxigenic Escherichia coli by using multiplex PCR assays for stx 1 , stx 2 , eaeA, enterohemorrhagic E. coli hlyA, rfbO111, and rfbO157. J Clin Microbiol. 36: 598-602. 